\title{
Classification of submersed aquatic vegetation of the Venice lagoon using MIVIS airborne data
}

\author{
Luigi Alberotanza $\left({ }^{1}\right)$, Rosa Maria Cavalli $\left({ }^{2}\right)$, Stefano Pignatti $\left({ }^{2}\right)\left({ }^{3}\right)$ and Angelo Zandonella $\left({ }^{4}\right)$ \\ (1) Istituto di Scienze Marine (ISMAR), CNR, Venezia, Italy \\ (2) Laboratorio Aereo Ricerche Ambientali (LARA), IIA-CNR, Tor Vergata (RM), Italy \\ $\left(^{3}\right)$ Istituto di Metodologie per l'Analisi Ambientale (IMAA), CNR, Tito Scalo (PZ), Italy
}

(') AdTec, Roma, Italy

\begin{abstract}
In July 2001 an aerial survey with MIVIS (Multispectral Infrared and Visible Spectrometer) hyperspectral sensor and an in situ survey campaign were performed on Venice lagoon to map benthic macro-algae and sea phanerogams distribution. On MIVIS VIS spectral range images, training areas for benthic macro-algae and sea phanerogams have been selected by using sea truth data collected by CNR-ISMAR from in situ campaign and periodic area surveys used in the lagoon by the local authorities. The derived spectral signature has been used to classify the area in order to produce the maps of the pure and mixture submersed vegetation population. The algorithm applied to the data is based on the Subpixel Spectral Analytical Process (SSAP) method. The method assumes that the spectrum of a single pixel is composed of a fraction of the material of interest while the remainder of the observed spectra contains background materials. In terms of recognition processes the produced maps present a very good agreement with the sea truth data even though the fraction material expressed in the maps does not represent a quantitative estimation of the material of interest.
\end{abstract}

Key words MIVIS - benthic macro-algae - sea phanerogams - subpixel classification

\section{Introduction}

Information on the submersed aquatic vegetation distribution in the Venice lagoon is of particular importance for the following reasons: i) environmental protection and therefore all the problems connected to pollution, eutrophication and water quality; ii) lagoon morphological control; iii) industrial use of some algae species.

Mailing address: Dr. Rosa Maria Cavalli, Laboratorio Aereo Ricerche Ambientali (LARA), IIA-CNR, Via del Fosso del Cavaliere 100, 00133 Tor Vergata (RM), Italy; email: cavalli@lara.rm.cnr.it
For these reasons submersed vegetation species recognition and mapping are periodically performed during the vegetative period by the local authorities. These activities are done to control the ecosystem status, to plan all activities of sea phanerogam plantation for the lagoon bottom morphological balancing and, in the past, for a selective harvesting of benthic macro-algae species.

Mapping techniques currently used are based on in situ observations and aerial photo-interpretations. For many years airborne and satelliteborne remote sensing images have been used to monitor the submersed vegetation distribution. The main airborne remote sensing airborne instruments were metric cameras, LIDAR systems, multispectral scanner systems while satelliteborne sensors were mainly Landsat TM.

The automatic detection of the vegetation was limited to vegetation cover and just to some 
species like Ulva rigida widely diffuse in time periods. The main reason for these difficulties in detecting vegetation could be ascribed to: i) the mixture of numerous submersed vegetation species, detectable in pixels of a few metres of spatial resolution; ii) the high level of water turbidity in the Northern and Central Basins of the lagoon; iii) the variability of the water thickness overhanging the submersed vegetation and modified by the tide conditions.

The methodological approaches proposed by researchers (Tonelli, 1987; Alberotanza et al., 1989, 1991; Baschieri et al., 1990; Tassan, 1990) to process data vary from band math operations to artificial intelligent techniques (i.e. neural networks).

In this section, a short discussion of the submersed vegetation spectral characteristics is reported and the procedures used for an automatic recognition of the more diffuse submersed vegetation species at the MIVIS data acquisition date is described.

\section{Spectral characteristics of the submersed vegetation}

The main spectral characteristics of submersed vegetation (fig. 1) in lagoon environments may be summarized as follows:

- Low reflectivity between 400 and $500 \mathrm{~nm}$ due to the absorption of blue light (maximum absorption at about $440 \mathrm{~nm}$ ).

- Maximum green reflectivity between 550 and $570 \mathrm{~nm}$.

- Low reflectivity between 660 and $690 \mathrm{~nm}$ due to red light absorption (maximum absorption between 670 and $680 \mathrm{~nm}$ ).

- Low reflectivity in the near infrared between 755 and $765 \mathrm{~nm}$ during pigmentation phase. An increasing of reflectivity occurs during blooming periods and in emerged vegetation conditions.

The substances responsible for the absorption of light are the chlorophyll pigments, carotenoids and other types of pigments.

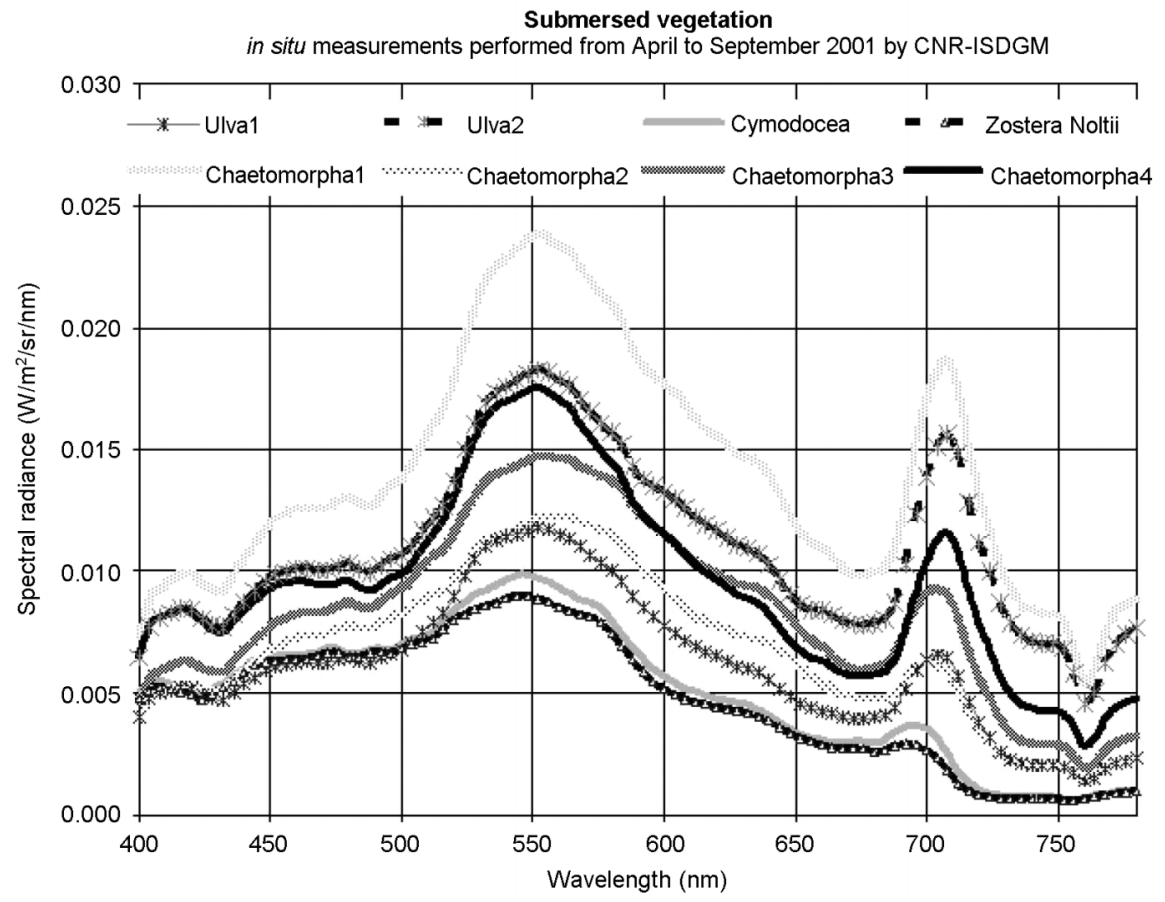

Fig. 1. Spectral radiance mean values of some submersed vegetation species. 
Chlorophyll-a is found in all green plants and is the predominant pigment in benthic macro-algae (absorption peaks at 440, 675, 695 $\mathrm{nm}$ of wavelength).

Other major pigments are phycoerythrin found in red macro-algae (absorption peak at 565 $\mathrm{nm}$ ), phycocyanin found in red and blue-green algae (absorption peak at $620 \mathrm{~nm}$ ), fucoxanthin (absorption peak at $470 \mathrm{~nm}$ ) (Wezermak et al., 1976).

These characteristics are derived from many investigations performed in the laboratory (Rundquist et al., 1996) and in lagoon, in different sites and growth conditions (Alberotanza et al., 1991), using portable filed spectrometers.

According to these observations, hyperspectral instruments seem to be more powerful in the discrimination of the lagoon submersed vegetation. In this framework the airborne hyperspectral MIVIS scanner presents a spectral band coverage useful for the study of the submersed vegetation. The visible part of the spectrum is covered by MIVIS through eighteen bands ranging between 443 and $783 \mathrm{~nm}$ of wavelength with a bandwidth of $20 \mathrm{~nm}$.

The main factors affecting the measurements of the submersed vegetation spectral signatures are: atmospheric effects; water turbidity; water thickness overhanging the submersed vegetation; presence of more species within a pixel of a few metres of resolution.

The effects of atmosphere are widely discussed in the literature.

Water turbidity in the lagoon is mainly due to upwelling sedimentation for tidal inflow effects, wind stress, phytoplankton blooms, organic substances in solution and, in recent years, to poachers. This effect generally misleads spectral reflectance measurements that may indicate the presence of a species different from the real one. Organic substances instead determine a change in the reflectance values in bands of the red and near-infrared (Gitelson, 1992; Rundquist et al., 1996). Phytoplankton blooming occurs in well known lagoon areas and periods of the year.

Water thickness overhanging the submersed vegetation depends on the bottom depth, the vegetation development phase and the tidal conditions. The lagoon mean water depth (excluding lagoon channels) is about $1 \mathrm{~m}$. In tidal inflow condition the mean water depth increases by about $40 \mathrm{~cm}$.

The mixing of vegetation species within a pixel determine for each pixel a composite spectral signature of pure species plus the lagoon bottom and atmospheric effects spectral contribution. Therefore from a remote sensing point of view the analytical approach is basically a subpixel mixture behaviour.

\section{MIVIS aerial survey}

The MIVIS aerial survey was performed on 26 July 2001 at 9:36 GMT from an altitude of $4000 \mathrm{~m}$ a.s.l. corresponding to a pixel spatial resolution of $8 \mathrm{~m}$. The aerial strip starts from Marco Polo Airport and ends over Chioggia city covering the areas with benthic macro-algae located in the Northern and Central Basins of the lagoon and a wide part of the area with sea phanerogams located in the Southern Basin of the lagoon.

Tidal conditions were in inflow tide starting conditions with a sea mean level of $4 \mathrm{~cm}$ at Punta della Salute. Consequently water thickness, overhanging the submersed vegetation in the Southern Basin, was estimated at about $50 \mathrm{~cm}$.

On the scene a negligible atmospheric haze and a high level of water turbidity in the Northern and Central Basins of the lagoon was detected by visual analysis of the quasi natural colour composite of MIVIS images.

\section{Image data processing}

The first eighteen MIVIS spectral bands were selected and pre-processed to obtain apparent reflectance data. The water body area was extracted using as mask image derived from thresholds applied to a histogram of MIVIS spectral band of $1500-1550 \mathrm{~nm}$. In order to minimize the scattering effects, Chaves (1988) method was applied to the MIVIS VIS spectral bands.

From sea truth data collected by CNR-ISDGM from in situ survey 2001 campaign and from periodic surveys in the lagoon performed by the local authorities, training areas for benthic macro-algae (Ulva rigida, Gracilaria confervoides, Chaetomorpha aerea) and sea phanerogams 
(Zostera marina, Zostera noltii, Cymodocea nodosa) were selected from the MIVIS data set.

Samples of Ulva rigida signatures were extracted in the area of Campalto channel, while samples of Gracilaria confervoides in the area in front of Marco Polo Airport. Additional samples of Cymodocea nodosa signatures were extracted in the area near Forte San Felice of Chioggia city, for Zostera noltii along the edges of Rocchetta channel.

The selected training areas were used to classify the surveyed area to determine the spatial distribution of the pure and mixture submersed vegetation population. The algorithm applied to the data is based on a particular implementation of the Subpixel Spectral Analytical Process (SSAP) method (Huguenin, 1994; Karaska et al., 1995).

SSAP method assumes that the spectrum of a single pixel is composed of a fraction of the material of interest (e.g., submersed vegetation specie) while the remainder of the observed spectra contains background materials (i.e. other minor vegetation species, mixture species, lagoon bottom). SSAP method detects the most abundant material of interest of the pixel under investigation by subtracting iteratively fractions of candidates background spectra. The background and fraction remainders that produce the residual spectrum closest to the spectrum of the material of interest are then identified. The output of this procedure is presented in the form of fraction planes (fraction maps) for each material of interest.

From a formal point of view, the method assumes no transmittance through the materials in at least one of the spectral bands. The radiant contributions of material of interest and those of background for the pixel «i» and the band $\langle j\rangle$, for $j=\{1, \ldots, N\}$, may be written as follows:

$$
R_{i}[j]=\left\{\left(f_{i}[j] \times M[j]\right)+\left(\left(1-f_{i}[j]\right) \times B_{i}[j]\right)\right\}
$$

where $R_{i}[j]$ is the spectral reflectance value of pixel «i» and band $\langle j » ; M[j]$ is the spectral reflectance value for the material of interest of the band $\langle j » ; M$ (spectral signature of the specie object of investigation) is assumed invariant from pixel to pixel; $B_{i}[j]$ is the spectral reflectance value for the background materials of pixel $\left\langle i »\right.$ and band $\left\langle j » ; f_{i}[j]\right.$ is the fraction of
$M$ for pixel «i» and band $\langle j »$. This fraction can vary from band to band, because the radiant contrast between the material of interest and the background can vary from band to band; (1+ $\left.-f_{i}[j]\right)$ is the fraction for the background materials of pixel $\langle i \gg$ and band $\langle j »$.

Each material of interest is searched for independently. The spectrum for the material of interest of a pixel is detected by subtracting, iteratively, fractions of candidate background spectra. For each candidate background, residuals are computed that produce the best spectral match to the spectrum for the material of interest.

The residual spectrum $M R_{i}[j]$ is computed as follows:

$$
M R_{i}=\frac{\left\{R_{i}[j]-\left(\left(1-f_{i}\right) \times B_{i}[j]\right)\right\}}{f_{i}}
$$

where $f_{i}$ is the identified fraction of the material of interest for pixel «i» and constant for each spectral band; $\left(1-f_{i}\right)$ is the fraction of background materials $B_{i}[j]$ removed from $R_{i}[j]$.

The residual spectrum found using this equation is considered valid when all of its values are greater than zero. An invalid residual indicates that a candidate background is not representative of the actual background for the pixel under investigation. If all the candidate backgrounds fail to generate a valid residual, then the pixel does not contain a detectable amount of the material of interest.

The degree of spectral match between the residual $M R_{i}[j]$ and the signature spectrum $M[j]$, is computed by minimizing, for each pixel «i»

$$
\frac{\left(\sum_{j=1}^{N}\left(M R_{i}[j]-M[j]\right)^{2}\right)}{(N-1)} .
$$

These methods were applied separately for the Northern and Central Basins (from Marco Polo Airport to Malamocco inlet) and for the Southern Basin (from Malamocco inlet to the end of aerial strip, i.e. over Chioggia city) due to the high water turbidity level in the Northern and Central Basins of the lagoon and the water transparency of the Southern Basin during the MIVIS survey.

In the computations as candidate backgrounds we considered the composite signatures 
extracted from the training areas using the described procedure for all combinations of the species under investigation plus a spectral signature of lagoon bottom without submersed vegetation for a total of 31 combinations.

\section{Discussion and conclusions}

For each species a fraction map was produced representing the material of interest in terms of percentage. For benthic macro-algae
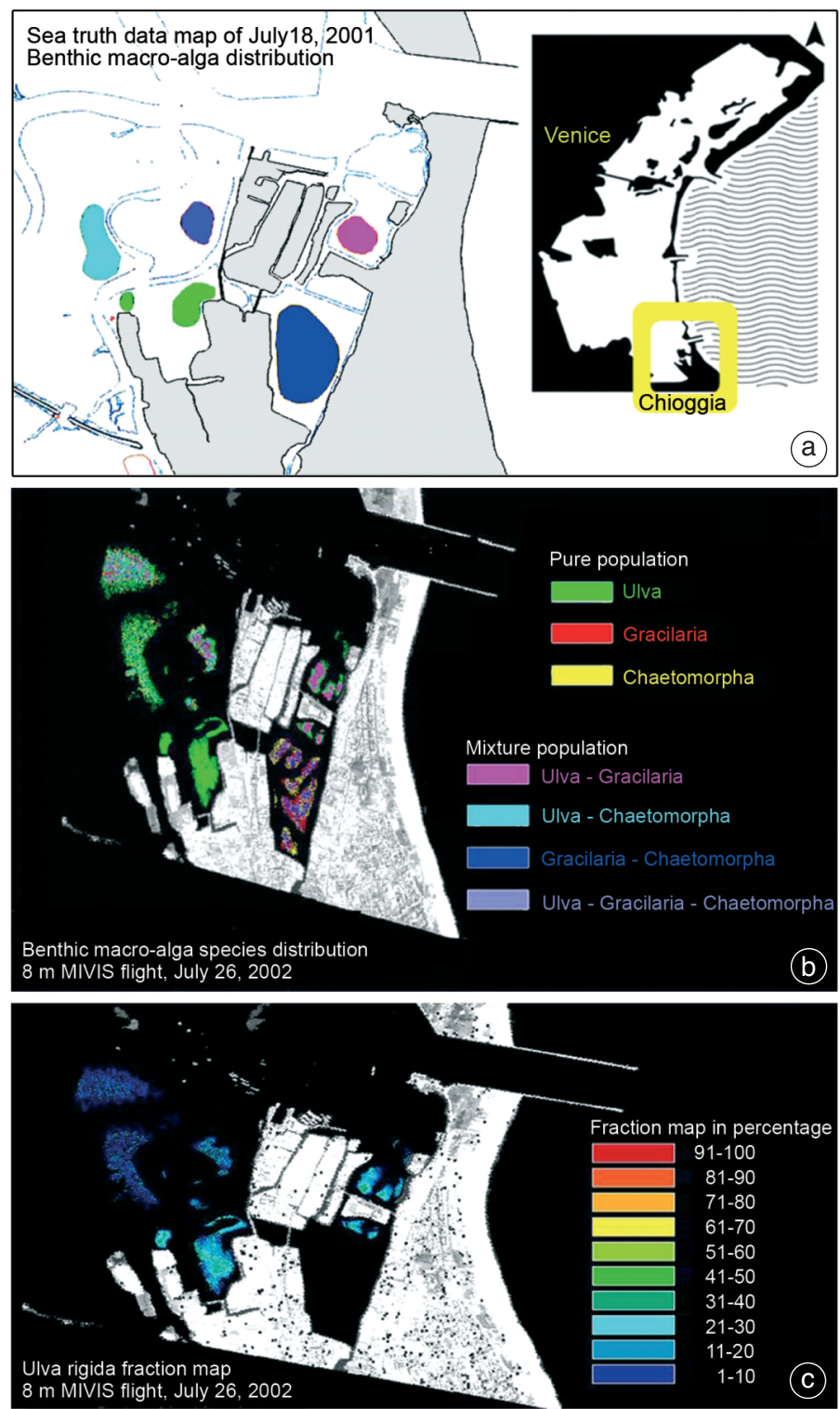

Fig. 2a-c. Subpixel classification results for the Chioggia city areas superimposed on the MIVIS spectral band of 1500-1550 nm. a) Sea truth data map; b) benthic macro-alga species distribution; c) Ulva rigida fraction map. 
and sea pha-nerogams the maps of pure and mixture species distribution were produced separately.

A subset of these maps for Ulva rigida (fig. 2c) and for the synthesis benthic algae map for the Chioggia city areas (fig. 2b) compared with the sea truth maps (fig. 2a) is shown in fig. 2a-c. In terms of recognition processes, the maps produced present a good agreement with the sea truth data even though the fraction material expressed in the maps of fig. 2a does not represent a quantitative estimation of the material of interest, because it is affected by scattering process occurring in the water column.

This particular implementation of the SSAP method currently represents the only approach to solve the complex problem of submersed vegetation species spectra classification for the Venice lagoon using the spectral information gathered by hyperspectral remote sensing instruments. This method has been used to spectrally separate pixel spectra (submersed vegetation species) that are from a static point of view highly significantly correlated.

Further developments of this classification procedure will include the correction of the water column effects to enhance the pixel spectra dynamic range and to achieve a realistic estimation of the fraction of the material of interest. This procedure will also be tested on the new hyperspectral space-borne data (EO-1/Hyperion) that on June 7, 2001 overpass the Venice Lagoon acquiring images in 225 spectral channels with a pixel spatial resolution of $30 \mathrm{~m}$.

\section{Acknowledgements}

The authors thank Nuova Telespazio SpA for funding their activities; Magistrato alle Acque di Venezia and Consorzio Venezia Nuova - Servizio Ambiente for the courtesy used in providing sea truth maps acquired within the projects for Venice and lagoon protection (Art. 3, Law 798/1984).

\section{REFERENCES}

Alberotanza, L., V. Belia, M. Pavanati and G. Zibordi (1989): Valutazione dei contenuti informativi di immagini multispettrali rilevati da scanner aerotrasportato per la stima della biomassa algale in bacini lagunari, in Proceedings of the Third AIT Symposium, 165-171.

Alberotanza, L., M. Pavanati, G. Zibordi and A. ZanDONELLA (1991): Landsat-5/TM images used to identify macroalgal vegetation in the Venice Lagoon, in $\mathrm{Wa}$ ter Pollution: Modelling, Measuring and Prediction, CMP - Elsevier Pub., 355-368

BASChIERI, P., V. MACAluso and A. Zandonella (1990): Venice Lagoon. An operating procedure for alga recognition using Landsat/TM data, in International Cartographic Association Symposium, Devoted to Thematic Mapping from Satellite Imagery, Paris, France, 326-338.

CHAVES, P.S. (1988): An improved dark-object subtraction technique for atmospheric scattering correction o multispectral data, Remote Sensing Environ., 24 (3), 459-479.

Gitelson, A. (1992): The peack near $700 \mathrm{~nm}$ on radiance spectra of algae and water: relationship of its magnitude and position with chlorophyll concentration, Int. J. Remote Sensing, 13, 3367-3373.

Huguenin, R.L. (1994): Subpixel analysis process improves accuracy of multispectral classification, Earth Obs. Mag., 3 (7), 37-40.

Karaska, M.A., R.L. Hunguenin, D. Van Blaricom and B. SAVITSKY (1995): Subpixel classification of cypress and tupelo trees in TM imagery, in Techical Papers of the American Society for Photogrammetry and Remote Sensing, Charlotte, North Caroline, 856-865

Rundquist, D.C., L. Han, J.F. Schalles and J.S. Peake (1996): Remote measurement of algal chlorophyll in surface waters: the case of the first derivative of reflectance near $690 \mathrm{~nm}$, Photogram. Eng. Remote Sensing, 62 (2), 195-200.

TASSAN, S. (1990): An algorithm for the identification of benthic algae in the Venice Lagoon from thematic mapper data, in Proceedings of the Second Conference on Oceans from Space, edited by J.F.R. GowER, Venice, Italy, 414-421.

Tonelli, A.M. (1987): Studio delle acque costiere con dati telerilevati: analisi multitemporale del trasporto solido e della flora sottomarina, in Proceedings of the First AIT Symposium, 41-54.

WEZERNAK, C.T., R.E. TURNER and D.R. LYZENGA (1996): Spectral reflectance and radiance characteristics of water pollutants, NASA CR-2665, 110-111. 